\title{
Research on Investment Decision of Scientific and Technology Insurance Based On the Expected Utility Model
}

\author{
Si-yun Xu \\ Science and Technology Financial Key Laboratory of Heb \\ ei Province \\ Department of Insurance \\ Hebei Finance University \\ Baoding, China
}

\author{
Hong-xian Gao \\ Department of Insurance \\ Hebei Finance University \\ Baoding, China
}

\author{
Yu-xia Wu \\ Science and Technology Financial Key Laboratory of Hebei Province \\ Department of Insurance \\ Hebei Finance University \\ Baoding, China
}

\begin{abstract}
Scientific and technological insurance is asocial sharing approach of scientific and technological risk and enterprises and the direct participants and beneficiaries in the insurance. Enterprise behavior in the scientific and technological insurance is critical to the stability of insurance system and stir of insurance process. So the study is very necessary. This paper analyses and discusses the enterprise behavior of all stages in scientific and technological insurance process. The expected utility entropy decision model is introduced briefly and then the decision model is applied in the field of investment decision, and focuses on scientific and technological insurance decision-making study by use of expected utility model.
\end{abstract}

Keywords: Scientific and technological insurance; Insurance Investment Decision-making; Scientific and technological risk; Enterprise Behavior; Excepted Utility Model

\section{INTRODUCTION}

The communist party of China since the eighteenth big, independent innovation is given in the change of industrial upgrading and economic growth in China's core power. Traditional industries need high and new technology to improve the reformation and the development of high-tech industries need to venture capital investment energetically. In recent years, with the deepening of the innovative national strategies in our country, the government pays more and more attention to the support of new and high technology research and development of insurance. In order to spread and transfer of science and technology enterprises in technology in recent years, with the deepening of the innovative national strategies in our country, the government pays more and more attention to the support of new and high technology research and development of insurance. In order to spread and transfer of technology companies in the technology development and management of the facing the high risk, China expands insurance pilot and the promotion of science and technology.

Accelerated the independent innovation of science and technology is the inevitable requirement of the full implementation of the scientific outlook on development and building a harmonious socialist society. In technology and insurance, such as economic development, social progress will play a key role. Insurance as a combination of both science and technology more is of great significance to strengthen capacity for independent innovation. At present, the insurance system innovation is effective efforts to promote science and technology, the study of the theory of the science and technology insurance also becomes hot spot gradually. Xueqing Shao, Zhichun Liu studied the government leading mode of science and technology insurance system framework design, puts forward the relevant policy recommendations. Hua Liu uses structural equation model to analyze the environment of science and technology, science and technology insurance's influence on the regional independent innovation ability. Ning Zhang, Susan take high and new technology enterprise of science and technology insurance demand is studied. From the point of science and technology insurance system, enterprise technology starts together with the insurance company insurance market main body. From the point of science and technology insurance process, enterprises involved in all phases of the science and technology insurance process so on science and technology insurance of enterprise behavior research has important theoretical and practical significance. But at present the research is relatively scarce, remains to be further. The stages of insurance in this paper, the technology process, namely the early insurance, insurance, reimbursement paper discusses enterprise behavior, finding out the existing key problems and reasons, and puts forward the guiding Suggestions. 


\section{Analysis the Insurance Decision In the Early Period}

Insurance marketing of science and technology is a comprehensive promote the combination of technology and financial major initiatives. At present, technology insurance has been to many sustained and rapid development of science and technology enterprises produced positive effect Insured upfront is the beginning of the science and technology insurance companies contact. At this stage, the behavior the results of companies directly decides the enterprise cognitive attitude towards science and technology insurance and insurance interest. The content is mainly to obtain insurance information and for sure will.

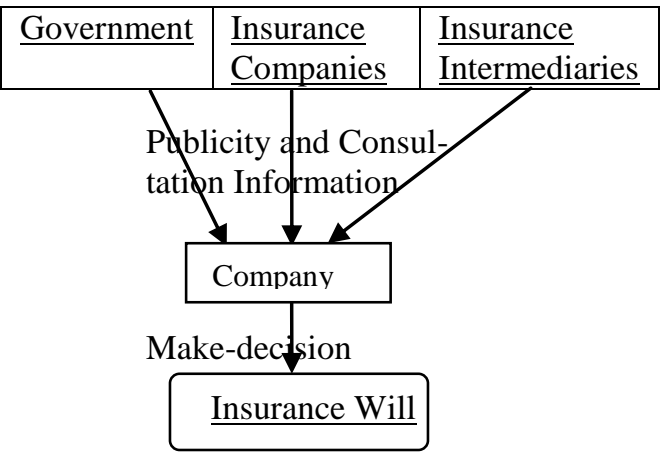

Fig. 1: The behavior about enterprise insurance.

\subsection{Collect and analyze relevant information}

Prior to the decision to insure, companies need to fully understand the relevant information of science and technology insurance. And the way to access to information is a twoway street. One is external stimuli, that is, government, insurance companies and insurance intermediary institutions for insurance propaganda and popularization of science and technology enterprise. Enterprises passively find from these external sources to accept some insurance information of science and technology. Second, independent access to information, that is, enterprises deeply research of science and technology innovation project risk is huge, it is difficult to bear alone. Or in other companies get good by science and technology insurance risk guarantee under the exemplary role of actively to the government and insurance companies and insurance intermediary consulting technology, access to relevant information.

At present our country has introduced technology can be divided into two major categories of life insurance and property insurance. Life insurance is aimed at science and technology enterprise research and development staff and senior managers. Personal insurance includes health insurance key staff and senior managers, key staff (special experiment personnel) accident injury insurance, etc. Property mainly for science and technology enterprise research and development (experiment) equipment and the final product, including the key research and development (experiment) equipment insurance, and final product quality guarantee insurance, the final product patent, etc. These two types of insurance in science and technology enterprise development, production, sales and marketing of 3 phase plays a different role, different influence on enterprise innovation and improve profitability.

\subsection{Make sure the Clear intention to insure}

Enterprise to understand science and technology insurance information, analysis of its own scientific research projects need to get the essence of science and technology insurance. These elements include such as equipment, responsibility, personnel, etc. The effect of these factors is whether science and technology insurance comply with relevant risks insured conditions.

If you can't determine whether accords with a condition, those can be referred to the insurance company or insurance intermediary institutions. Whether meet the conditions for insurance elements, eventually enterprises also need to consider some other factors. These other factors including technology insurance and other risk way of comparison, insurance rate of science and technology level, level of government subsidies, the credibility of insurance company, etc.

Analysts after balance, to determine whether or not insured. Science and technology insurance, life insurance attracts high technical talents and management talents to join and stable team and senior management team, and improve enterprise innovation ability. This advantage is mainly reflected in two aspects. First of all, most enterprise staff engaged in mental Labor, of science and technology work pressure big, high physical quality requirements. If the enterprise can provide high technical talents and management talents with generous health insurance and health insurance, can when recruiting talented people attention, increase the introduction of talent advantages, innovation ability for its potential power. Second, a lot of research and development find the strength in science and technology enterprises, such as biology, medicine, chemistry experiment, etc. Health risk, if the enterprise for the risks in the insurance, can reduce staff stress, directly promote enterprise innovation ability to ascend.

\section{Analysis Behavior of the Insurance Decision In the Period}

To the insurance company, after the enterprises determine insurance will request insurance, formally entered the stage of insurance. Insured stage is the key link in the whole process of science and technology insurance, related to science and technology to establish the relationship between the interests of insurance parties. Enterprise with science and technology insurance contracts in this phase, establish insurance relationship of science and technology as the goal. The phase behavior including understand claus- 
es; submit insurance and insurance scheme negotiation three parts.

\subsection{Understand the insurance clause}

After the insurance company accept insurance requirements, will introduce to the science and technology insurance clauses. As science and technology insurance participants, enterprises should read the clauses of science and technology. In particular, the main content of insurance clauses is the scope of insurance liability, liability exemption part, etc. This section is used to clear themselves and their insurance company to assume responsibility and fulfill obligations. If business disputes about insurance clauses insurance company can be demanded an explanation, until approved insurance clauses. If finally cannot accept insurance clause, the insurance company can give up.

\subsection{Submit to insure information}

After enterprise recognition technology clauses, shall be submitted to the insurance company insurance information. Due to insure materials it is insurance company insured the real important source of information, the insurance company in order to reduce adverse selection, and carefully review insurance data, evaluate risk. If do not conform to the science and technology insurance concept, the insurance company will refuse to accept insurance. So enterprises shall abide by the principle of honesty insurance, provide detailed real insurance information.

\subsection{Negotiate about Insurance Scheme}

If the enterprise insurance information is complete, and in line with the concept of science and technology insurance underwriting insurance risk, insurance company is making insurance plan and submit the enterprise of science and technology. Subsequently, the insurance company insurance plans to negotiate with the enterprise. If there were divided between two sides, they can jointly modify insurance scheme in under the premise of the two sides agreed to by both parties, until the agreement. Insurance companies' insurance certificate marks the establishment of insurance relationship of science and technology.

\section{Expected Utility Model of Science and Technology Insurance}

Von Neumann and Morgenstern's expected utility model is on the basis of the axiomatic hypothesis, using the logical and mathematical tools, set up under the condition of uncertainty of rational people choose the theory of analysis method. Enterprise is the purpose of insurance technology with the insurance company for research and development innovation risk. The goal is to maximize its own utility, so the model can be used in science and technology in the study of decision-making behavior of insurance companies covered.

\subsection{The Theoretical Concept}

Expected utility model involves the expected utility and the expected utility of two common concepts. Expected utility refers to, if a random variable $\mathrm{Y}$ with probability $\mathrm{Yi}$ $(i=1,2, \ldots)$ value of Pi. When the Yi gets the utility $U(Y)$, the excepted utility formulation is

$$
A U=P_{i} U\left(Y_{i}\right), i=1,2,3 \ldots, n \text {. }
$$

There are two possible states that the enterprise need to face after insurance technology_— the compensation after the accident or not compensation without accident. Let us assume that the incident probability is $\mathrm{Pl}, 0<\mathrm{Pl}<1$, and enterprise income respectively under the two states is y1, y2. So, enterprise expected utility formulation is

$A U=P U\left(y_{1}+v-j\right)+(1-p) U\left(y_{2}-j\right)$

\subsection{Model Analysis}

This part will use the model to analysis the enterprise behavior when it wants to get the max utility facing the risk.

We get the enterprise expected utility formulation in the last part. In the $A U=P U\left(y_{1}+v-j\right)+(1-p) U\left(y_{2}-j\right)$, there are a positive relationship between the companies $\mathrm{v}$ and the fee of insurance. If we assume the $v=1$, and the $j>0$, the max enterprise expected utility formulation is

$M A X A U=P U\left(y_{1}+j_{i}-j\right)+(1-p) U\left(y_{2}-j\right)(3)$

To solve differential coefficient is the good way to get the $\max \mathrm{j}$. So, we could design the formulation as following:

$\frac{U^{\prime}\left(y_{1}+j s-j\right)}{U^{\prime}\left(y_{2}-j\right)}=\frac{1-p}{p(k-1)}$

On the other side, the insurance company can get the benefit $\mathrm{j}$-jk when the accident happened, or get the benefit $\mathrm{p}(\mathrm{j}$ $\mathrm{jk})+\mathrm{j}(1-\mathrm{p})$ without accident. Assuming the insurance market without exception, the excepted utility wills maximize when

$U^{\prime}\left(y_{1}+j s-j\right)=U^{\prime}\left(y_{2}-j\right)$

\section{Conclusion}

Using expected utility entropy decision model, this paper evaluates the effect of science and technology insurance and which point we can achieve expected utility maximization. The results showed that when the enterprise of science and technology insurance premium in the after the incident of the marginal utility is equal to the marginal utility of the former, insurance to achieve the expected utility maximization.

\section{Acknowledgements}

The research work was supported by Hebei Province Department of Science and Technology under Grant

(No. 15457636D) 


\section{References}

[1] Yang J,Qiu W, "A measure of risk and a decision making model based on expected utility and entropy," European Journal of Operational Research, pp. 792$799,2005$.

[2] Liu H. "Optimal consumption and investment with transaction costs and multiple risky assets," The Journal of Finance, pp. 289-338,2004.
[3] Zuoxiong Zhang, “Agricultural Insurance Business Model Selection and Development of Ideas in Jiangsu Provence," Proc. China Insurance, pp. 2010(2).

[4] Yuhuan Liu, Changyue Li, "The market survey report about how to develop small insurance," Proc. Rural Finance Research, pp. 34-38, 2010.

[5] Duffie D J, Epstein L G, "Asset pricing with stochastic differential utility," Review of Financial studies, pp. $411-436,1992$. 